\title{
CORRECTIONS TO THE LUNISOLAR PRECESSION AND THE MOTION OF THE EQUINOX FROM PROPER MOTIONS OF CEPHEIDS
}

\author{
A. M. SINZI \\ Astronomical Division, Hydrographic Department, Tokyo, Japan
}

(Presented at IAU Colloquium No. 9, 'The IAU System of Astronomical Constants', Heidelberg, Germany, August 12-14, 1970.)

\begin{abstract}
Corrections to Newcomb's lunisolar precession and to motion of the equinox are evaluated from proper motions of 77 Cepheids, employing recently determined values of their distances. Results are diverse, depending on the weighting method. If the effect of the cosmic dispersion is neglected and $\omega_{0}$ is imposed to be $25 \mathrm{~km} / \mathrm{s} / \mathrm{kpc}$, then $\Delta p_{1}=1 " 1 \pm 0 ! 2$ and $\Delta \lambda^{\prime}+\Delta e=1 " 0 \pm 0$ "1 per century in the FK4 system.
\end{abstract}

\section{Procedure}

Corrections to Newcomb's lunisolar precession and to the motion of the equinox together with the galactic rotation velocity are evaluated from proper motions of Cepheids. The same procedure as that of Weaver and Morgan (1956) is applied. Basic equations are:

$$
\begin{aligned}
& -\omega_{0} \cos b \cos \phi+\kappa \Delta n \cos \delta(\cot \varepsilon+\sin \alpha \tan \delta)-\kappa\left(\Delta \lambda^{\prime}+\Delta e\right) \cos \delta \\
& =\kappa\left(15 \mu_{\alpha} \cos \delta\right)-\frac{U_{0}}{r} \sin \alpha+\frac{V_{0}}{r} \cos \alpha \\
& -R_{0} \Delta \omega(R)\left(\frac{\cos l}{r \cos b}-\frac{1}{R_{0}}\right) \cos b \cos \phi-R_{0} \Delta \omega(R) \sin l \frac{\sin b}{r} \sin \phi \\
& -\omega_{0} \cos b \sin \phi+\kappa \Delta n \cos \alpha \\
& =\kappa \mu_{\delta}-\frac{U_{0}}{r} \cos \alpha \sin \delta-\frac{V_{0}}{r} \sin \alpha \sin \delta+\frac{W_{0}}{r} \cos \delta \\
& -R_{0} \Delta \omega(R)\left(\frac{\cos l}{r \cos b}-\frac{1}{R_{0}}\right) \cos b \sin \phi+R_{0} \Delta \omega(R) \sin l \frac{\sin b}{r} \cos \phi
\end{aligned}
$$

Symbols have their customary meanings: $\omega$, angular velocity of the galactic rotation; $\Delta p_{1}=\Delta n / \sin \varepsilon$; correction to the lunisolar precession; $\Delta \lambda^{\prime}$, correction to the planetary precession; $\Delta e$, correction to motion of the equinox; $U_{0}, V_{0}, W_{0}$, the solar motion components; $\phi$, parallactic angle; $R$, distance from the galactic centre; $r$, distance from the Sun. Suffix 0 refers to the position of the Sun and $\Delta \omega=\omega-\omega_{0} . R_{0}$ is taken as $10 \mathrm{kpc}$.

In the right-hand side of each equation above, $U_{0}, V_{0}, W_{0}$ and $R_{0} \Delta \omega(R)$ are obtained 
from distances and radial velocities of Cepheids. Then, $\omega_{0}$ and $\Delta n$ are obtained from (2) and are substituted into (1) to evaluate $\left(\Delta \lambda^{\prime}+\Delta e\right)$.

In the formation of normal equations two kinds of weights are assigned to the individual proper motions, i.e.

and

$$
w_{1}=\frac{w_{r}}{\sigma_{\mu_{i}}^{2}+\left(\frac{\sigma_{t}}{\kappa r}\right)^{2}}
$$

$$
w_{2}=\frac{w_{r}}{\sigma_{\mu_{i}}^{2}} .
$$

Here, $w_{r}$ is taken as 2 or 1 according to the reliability of the distance determination. For $\sigma_{\mu_{t}}$ the probable error of the proper motion for each star is employed. As for the effect of the cosmic dispersion, $\sigma_{t}$ is taken as $10 \mathrm{~km} / \mathrm{s}$ tentatively.

\begin{tabular}{|c|c|c|c|c|c|c|}
\hline \multirow[t]{2}{*}{ System } & \multirow{2}{*}{$\begin{array}{l}R_{0} \Delta \omega(R) \\
\text { Weight }\end{array}$} & \multicolumn{2}{|c|}{$\begin{array}{l}\text { All available radial } \\
\text { velocities }\end{array}$} & \multicolumn{2}{|c|}{$\begin{array}{l}\text { Radial velocities of } \\
\text { cepheids in } \\
-2<R-R_{0}<+2.5 \mathrm{kpc}\end{array}$} & \multirow{2}{*}{$\begin{array}{l}\text { Weaver } \\
\text { and } \\
\text { Morgan } \\
\text { (1956) }\end{array}$} \\
\hline & & $\begin{array}{l}\text { With } \\
\text { cosmic } \\
\text { dispersion }\end{array}$ & $\begin{array}{l}\text { Without } \\
\text { cosmic } \\
\text { dispersion }\end{array}$ & $\begin{array}{l}\text { With } \\
\text { cosmic } \\
\text { dispersion }\end{array}$ & $\begin{array}{l}\text { Without } \\
\text { cosmic } \\
\text { dispersion }\end{array}$ & \\
\hline \multirow{6}{*}{ N30 } & \multicolumn{6}{|c|}{$\mathrm{km} / \mathrm{s} / \mathrm{kpc}$} \\
\hline & $\begin{array}{l}\omega_{0} \\
\text { p.e. }\end{array}$ & $\begin{array}{r}17.3 \\
\pm \quad 3.8\end{array}$ & $\begin{array}{r}26.2 \\
\pm \quad 2.7\end{array}$ & $\begin{array}{r}19.3 \\
+\quad 3.8\end{array}$ & $\begin{array}{r}28.6 \\
\pm \quad 2.7\end{array}$ & $\begin{array}{r}23.2 \\
+\quad 3.4\end{array}$ \\
\hline & \multicolumn{5}{|c|}{ per century } & \\
\hline & $\begin{array}{l}\Delta p_{1} \\
\text { p.e. }\end{array}$ & $\begin{array}{r}0^{\prime \prime} .66 \\
+\quad 0.28\end{array}$ & $\begin{array}{r}1 " 13 \\
+0.21\end{array}$ & $\begin{array}{r}0.71 \\
+\quad 0.28\end{array}$ & $\begin{array}{r}1 " 18 \\
+\quad 0.22\end{array}$ & $\begin{array}{r}0.76 \\
+0.26\end{array}$ \\
\hline & \multicolumn{6}{|c|}{ per century } \\
\hline & $\begin{array}{l}\Delta \lambda^{\prime}+\Delta e \\
\text { p.e. }\end{array}$ & $\begin{array}{l} \pm 0.63 \\
\pm 0.10\end{array}$ & $\begin{array}{l} \pm 0.93 \\
\pm 0.07\end{array}$ & $\begin{array}{l} \pm 0.65 \\
\pm 0.10\end{array}$ & $\begin{array}{l} \pm 0.96 \\
\pm 0.07\end{array}$ & $\begin{array}{l} \pm 0: 78 \\
\pm 0.07\end{array}$ \\
\hline \multirow{6}{*}{ FK4 } & \multicolumn{6}{|c|}{$\mathrm{km} / \mathrm{s} / \mathrm{kpc}$} \\
\hline & $\begin{array}{l}\omega_{0} \\
\text { p.e. }\end{array}$ & $\begin{array}{r}18.9 \\
+\quad 3.6\end{array}$ & $\begin{array}{r}29.0 \\
+\quad 2.6\end{array}$ & $\begin{array}{r}20.8 \\
\pm \quad 3.6\end{array}$ & $\begin{array}{r}31.4 \\
\pm \quad 2.6\end{array}$ & \\
\hline & \multicolumn{6}{|c|}{ per century } \\
\hline & $\begin{array}{l}\Delta p_{1} \\
\text { p.e. }\end{array}$ & $\begin{array}{r}0.55 \\
\pm \quad 0.27\end{array}$ & $\begin{array}{r}1 / .33 \\
\pm 0.21\end{array}$ & $\begin{array}{r}0.60 \\
\pm \quad 0.27\end{array}$ & $\begin{array}{r}1 \text { 1"38 } \\
\pm \quad 0.21\end{array}$ & \\
\hline & \multicolumn{6}{|c|}{ per century } \\
\hline & $\begin{array}{l}\Delta \lambda^{\prime}+\Delta e \\
\text { p.e. }\end{array}$ & $\begin{array}{r}0^{\prime \prime} 75 \\
\pm \quad 0.08\end{array}$ & $\begin{array}{r}1.05 \\
\pm \quad 0.07\end{array}$ & $\begin{array}{r}0.78 \\
+\quad 0.08\end{array}$ & $\begin{array}{r}1 " 104 \\
\pm \quad 0.07\end{array}$ & \\
\hline
\end{tabular}

\section{TABLE I}




\section{Data}

Distance and radial velocity data are mostly taken from the catalogue of Fernie and Hube (1968) with a few additions from the table of Kraft and Schmidt (1963). Crampton and Fernie's (1969) values of the solar motion are directly adopted. The relation between $R_{0} \Delta \omega$ and $R$ is empirically determined from (i) all available radial velocities of 133 Cepheids and (ii) radial velocities of 125 Cepheids which lie in the range $-2<R-R_{0}<+2.5 \mathrm{kpc}$, since the Cepheids whose proper motion data are available are distributed in this range.

Proper motion data of 77 Cepheids are taken from Weaver and Morgan's (1956) material on the N30 system. For reducing these values to the FK4 system, systematic differences by Brosche et al. (1964) are applied for each star.

\section{Result}

The solutions of the least squares method are given in Table I. Since most of the

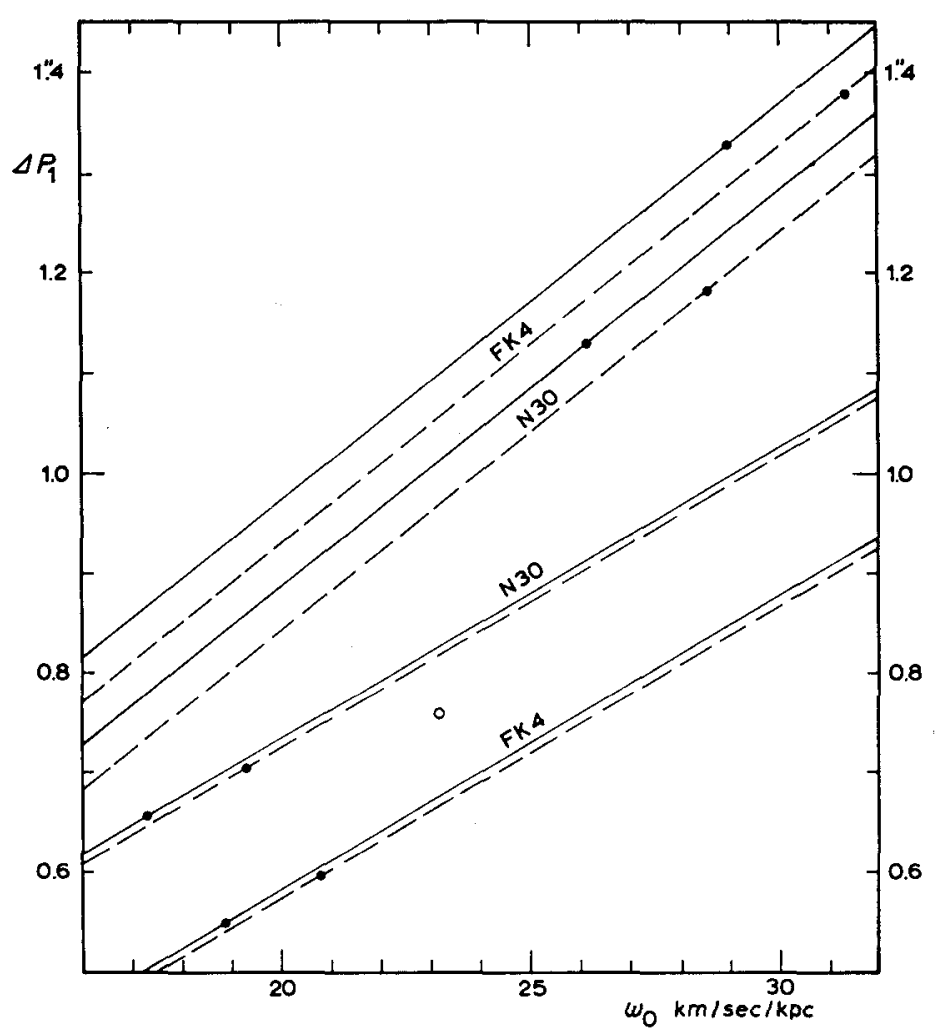

Fig. 1. $\Delta p_{1}$ against $\omega_{0}$. Upper 2 sets: weight without cosmic dispersion. Lower 2 sets: weight with cosmic dispersion. $R_{0} \Delta \omega$ from radial velocities of: all available Cepheids; ........- nearby Cepheids; least squares solutions; $O$ Weaver and Morgan (1956). 


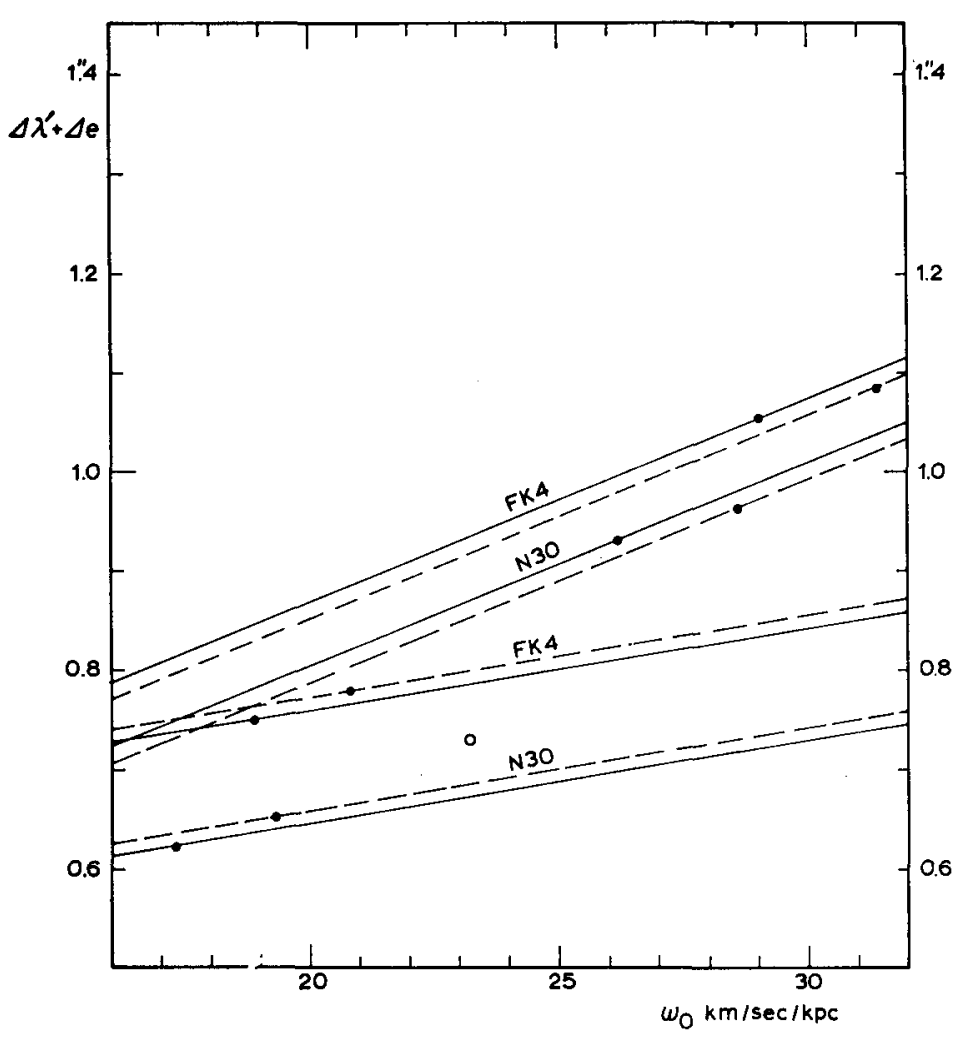

Fig. 2. $\Delta \lambda^{\prime}+\Delta e$ against $\omega_{0}$. Upper 2 sets: weight without cosmic dispersion. Lower 2 sets: weight with cosmic dispersion. $R_{0} \Delta \omega$ from radial velocities of: - all available Cepheids; -...-..nearby Cepheids; least squares solutions; $O$ Weaver and Morgan (1956).

values of $\omega_{0}$ seem to be rather unlikely, $\Delta n$ and $\left(\Delta \lambda^{\prime}+\Delta e\right)$ are evaluated by assigning various values of $\omega_{0}$. The results are shown in Figures 1 and 2. Their probable errors are almost the same as those of the least squares solutions in Table I, respectively. In Figures 1 and 2, dots show the least squares solutions and circles the values by Weaver and Morgan (1956).

\section{References}

Brosche, P., Nowacki, H., and Strobel, W.: 1964, Veröff. Astron. Rechen-Institut Heidelberg No. 15. Crampton, D. and Fernie, J. D.: 1969, Astron. J. 74, 53.

Fernie, J. D. and Hube, J. O.: 1968, Astron. J. 73, 492.

Kraft, R. P. and Schmidt, M.: 1963, Astrophys. J. 137, 249.

Weaver, H. F. and Morgan, H. R.: 1956, Astron. J. 61, 268. 